\title{
Constrictive pericarditis in rheumatoid arthritis
}

\author{
A K THOULD
}

From the Department of Rheumatology, Royal Cornwall Hospital (City), Truro, Cornwall

SUMMARY Constrictive pericarditis is an unusual complication of rheumatoid arthritis, and its development appears to be uninfluenced by second-line therapy. Five patients are described who developed the disease, with possibly two more. Medical treatment is ineffective: the treatment of choice is surgical, and the postoperative prognosis is good. The crude prevalence rate for the association is $0.64 \%$ for males and $0.06 \%$ for females.

Constrictive pericarditis was first described by Lower in $1669 .{ }^{1}$ and the relationship between constrictive pericarditis and rheumatoid arthritis was possibly first noted by Charcot. ${ }^{2}$ Garrod believed that the heart was rarely affected in rheumatoid arthritis, ${ }^{3}$ but others have drawn attention to the fact that the association is rarely diagnosed in life. ${ }^{4}$ It affects males more frequently than females, ${ }^{5}$ in contrast with rheumatoid arthritis in general. It is thought to be uncommon in patients with arthritis of longer than six years' duration, ${ }^{6}$ and a recent leader ignored rheumatoid arthritis as a cause altogether. ${ }^{7}$ The relation with subcutaneous rheumatoid nodules has been noted, ${ }^{\circ}$ and the prognosis has been shown to be very poor unless the constriction is relieved surgically. ${ }^{9}$ Medical treatment appears to be ineffective. ${ }^{5}$ We report five more patients with constrictive pericarditis complicating their rheumatoid arthritis, together with two more in whom there was a strong probability. Clinical details of these patients are given in Table 1.

\section{Case reports}

CASE 1

A white female aged 38 years at the time of her operation had a 12 year history of seropositive rheumatoid arthritis affecting most joints and associated with subcutaneous nodules in the wrists and right heel. When living abroad she developed a servere vasculitis of the fingers and toes, with extensive dermal infarction of the dorsum of the right foot. She returned to the United Kingdom in 1983 and was referred to our department. Severe vasculitis of the fingers and toes was still present together with her nodules, and hand and feet radiography showed extensive erosive disease. The

Accepted for publication I July 1985

Correspondence to Dr A K Thould.
Rose-Waaler test was positive at a titre of $1 / 2048$, the C-reactive protein was $25.0 \mathrm{mg} / \mathrm{l}$, plasma viscosity $1.83 \mathrm{cP}$, and haemoglobin $14.9 \mathrm{~g} / \mathrm{dl}(149 \mathrm{~g} / \mathrm{l})$. Antinuclear factor was positive with eight DNA antibody units $/ \mathrm{ml}$. She had a loud pericardial friction rub, and chest radiograph showed a large, globular heart. Echocardiography confirmed a large pericardial effusion. She had ascites, hepatomegaly, and elevation of the jugular venous pressure. The electrocardiogram (ECG) was normal. Treatment was started with diuretics, azathioprine $50 \mathrm{mg}$ three times a day and prednisolone $25 \mathrm{mg}$ daily, but a week after an initial improvement with reduction in heart size her systolic blood pressure fell to 90 $\mathrm{mmHg}$ and the urea rose to $12.7 \mathrm{mmol} / \mathrm{l}$. Because it was feared that she had a severe cardiac tamponade, after an initial unsuccessful pericardial paracentesis she was transferred to the Brompton Hospital ( $\mathrm{Mr}$ Paneth) just four weeks after her large pericardial effusion was noted on echocardiography. A paracentesis of the pericardium was carried out removing $100 \mathrm{ml}$ of fluid. At operation the diagnosis was confirmed and the pleural cavity was found to be obliterated by fine tenacious adhesions: the pericardial space was totally obliterated. A large window was made anterior to the phrenic nerve and a smaller one posteriorly. She made an uneventful and excellent recovery, and her vasculitis steadily improved. Her dermal infarct was successfully skin grafted, and she has remained well on azathioprine $50 \mathrm{mg}$ daily and prednisolone $2.5 \mathrm{mg}$ at night.

\section{Histology (Dr B J Addis)}

The pericardium was greatly thickened by collagenous fibrous tissue covered on one aspect by an organising fibrinous exudate containing a number of cholesterol crystal clefts. There were a few perivascular aggregates of lymphocytes but no features to specifically suggest rheumatoid pericarditis. 


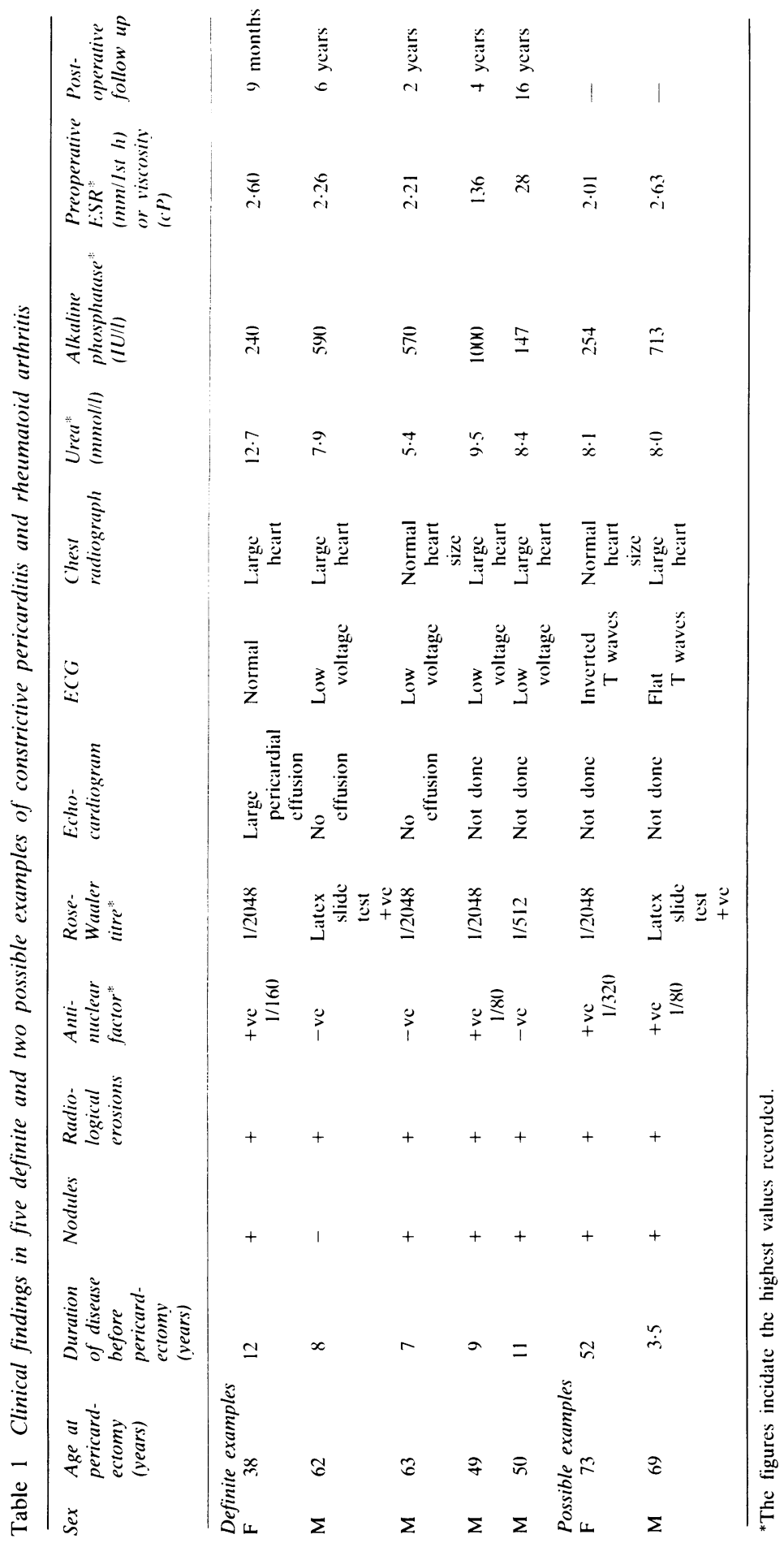


CASE 2

The patient was a white male aged 62 years at the time of his cardiac surgery. He first came to our department in 1976 with an 18 month history of rheumatoid arthritis with an extensive polyarthralgia. He was seropositive for rheumatoid factor, with an erythrocyte sedimentation rate (ESR) of 25 $\mathrm{mm} / 1 \mathrm{st} \mathrm{h}$, a haemoglobin of $14 \cdot 3 \mathrm{~g} / \mathrm{dl}(143 \mathrm{~g} / \mathrm{l})$, and many erosions were seen in his hand and feet radiographs. He was a heavy smoker. Later that year he developed a right pleural effusion and his ESR had risen to $55 \mathrm{~mm} / 1 \mathrm{st} \mathrm{h}$. Treatment was started with penicillamine, building up to $500 \mathrm{mg}$ daily over four months. No rheumatoid nodules were seen. In the summer of 1977 he developed a pericardial friction rub with elevation of the jugular venous pressure and considerable hepatomegaly. The ECG was normal. The urea had risen from normal to $9.8 \mathrm{mmol} / \mathrm{l}$. The antinuclear factor was negative. Over the next five years his pericardial rub was heard intermittently, but the hepatomegaly and elevation of jugular venous pressure returned to normal. In March 1982 he had a recurrence of his pericardial rub, hepatomegaly, and marked elevation of the jugular venous pressure, and a chest radiograph showed moderate cardiac enlargement. The echocardiograph did not show any evidence of a pericardial effusion. A diagnosis of constrictive pericarditis was made, and he was referred to the Brompton Hospital (Mr Lennox). At thoracotomy a large quantity of greenish-brown pleural fluid was aspirated and $700 \mathrm{ml}$ of fluid removed from the pericardial sac. A large pericardial window anterior to the phrenic nerve was fashioned, and he made an excellent postoperative recovery. The right pleural effusion disappeared over the next seven months. $\mathrm{He}$ remains well on penicillamine $500 \mathrm{mg}$ daily and an Indocid suppository, with no recurrence of his pericardial signs.

\section{Histology (Dr B J Addis)}

The pleura and pericardium showed marked collagenous thickening and patchy chronic inflammatory infiltrate.

\section{CASE 3}

The patient was a white male aged 63 years when he had his operation, whose rheumatoid arthritis began in 1975. He started penicillamine three years later. When he was first seen in our department in 1980 he was receiving $500 \mathrm{mg}$ penicillamine daily and his rheumatoid arthritis was still active. He had subcutaneous nodules of both elbows, a plasma viscosity of $2.03 \mathrm{cP}$, a haemoglobin of $14 \cdot 0 \mathrm{~g} / \mathrm{dl}(140 \mathrm{~g} / \mathrm{l})$, and he was seropositive for rheumatoid factor. He improved over the next three years, and his penicil- lamine was first reduced to $375 \mathrm{mg}$ daily and then stopped altogether in 1982 because of severe proteinuria. In January 1983 he developed ankle oedema, hepatomegaly, and raised jugular venous pressure with a persistent pericardial friction rub. He was diagnosed as having constrictive pericarditis and transferred to the Brompton Hospital ( $\mathrm{Mr}$ Paneth). His urea was $5.4 \mathrm{mmol} / \mathrm{l}$ and the creatinine clearance $46 \mathrm{ml} / \mathrm{min}$. The antinuclear factor was negative, but the Rose-Waaler test was positive at a titre of 1 in 2048. Echocardiography did not show any pericardial effusion. Rectal biopsy was negative for amyloid. The ECG showed a small voltage tracing and a biphasic $P$ wave in lead $V_{1}$. Chest radiograph did not show cardiac enlargement but did show small bilateral pleural effusions. Endomyocardial biopsy was normal. At operation the heart was found to be encased in a thick-walled pericardial sac. The pericardium was excised, but the epicardium was too adherent to remove so it was cross hatched. Many pleural nodules were noted: there was no evidence that these were due to asbestosis, though there was a history of exposure. It was thought likely that the epicardium might cause further constriction later. Postoperative recovery was complicated by a small abscess in the chest wound but was otherwise normal. He has remained well on non-steroidal anti-inflammatory drugs since, though his urea has risen to $14.3 \mathrm{mmol} / \mathrm{l}$ and respiratory function studies have shown pulmonary fibrosis associated with his pleural nodulation. This has been thought to be related to his rheumatoid arthritis.

\section{Histology (Dr B J Addis)}

The pericardium was thickened by organising fibrin and infiltrated by lymphocytes and plasma cells. Rheumatoid granulomas were not observed, and the appearances were those of a moderate non-specific chronic inflammation.

\section{CASE 4}

A white male aged 49 years at the time of his operation first came to our department in 1971 with a two month history of typical rheumatoid arthritis. He was seropositive for rheumatoid factor, with an ESR of $15 \mathrm{~mm} / 1 \mathrm{st} \mathrm{h}$, and he was noted to have subcutaneous nodules around the elbows. Hand and feet radiography only showed juxta-articular osteoporosis. In 1976 he developed ascites, a small pleural effusion, and an enlarged heart on chest radiograph. A pericardial friction rub was noted occasionally. In 1979 he developed hepatomegaly, and a liver biopsy showed some fibrosis, bile duct proliferation, and swelling of the hepatocytes, with areas of cell necrosis and fatty degeneration. There 
was no evidence of amyloidosis. Subsequently he developed a thrombosis of the innominate vein, with swelling of the left arm, and it was feared that there might be a malignant cause. Laparotomy ( $\mathrm{Mr} \mathrm{R} \mathrm{F}$ Adlington) showed no obvious abnormality, however, and he subsequently improved. In late 1979 his rheumatoid arthritis flared up again and treatment with penicillamine was started, building up to 500 $\mathrm{mg}$ daily. The plasma viscosity was $2.34 \mathrm{cP}$, and the Rose-Waaler test was positive at a titre of $1 / 2048$. The antinuclear factor was negative. He continued to have a small right pleural effusion, and in February 1980 this became bilateral with a recurrence of his pericardial friction rub. The ECG showed a low voltage tracing, in sinus rhythm. His hepatomegaly had worsened, and he was diagnosed as having constrictive pericarditis. Rectal biopsy was negative for amyloid. He was transferred to the Brompton Hospital (Mr Lennox) where a pericardectomy was carried out. The pericardium was 4 mm thick and most of it was dissected off the heart and excised, including the diaphragmatic pericardium. He made a good postoperative recovery, with resolution of his hepatomegaly and pleural effusions over the next two months, and he has remained well on penicillamine $500 \mathrm{mg}$ daily. The antinuclear factor has subsequently become positive with five DNA antibody units/ml present.

\section{Histology \\ Unavailable.}

CASE 5

A white male aged 50 years at the time of his surgery had had rheumatoid arthritis since 1957, and he was found to be seropositive for rheumatoid factor. Later he produced subcutaneous nodules around the elbows, and in 1958 he developed right sided pleurisy and a pleural effusion. He was thought to be tuberculous, though his sputum was negative on culture. He was started by the Chest Department (Dr B A G Jenkins) on streptomycin, PAS, and INAH for one year with no effect, and the pleural effusion continued. He was found to have erosions on his hand and feet radiographs, and in 1966 he developed hepatomegaly and a raised jugular venous pressure. An enlarged heart was seen on his chest radiograph, and two months later he developed a pericardial friction rub. Treatment was started with non-steroidal anti-inflammatory drugs and prednisolone $5 \mathrm{mg}$ daily. The next year a diagnosis of constrictive pericarditis was made. He was referred to the Brompton Hospital (Mr Paneth) and an extensive pericardectomy and decortication of the left lung was performed. An ECG showed an inverted $T$ wave in leads $A V_{L}, A V_{F}, I$, II, and $V_{2-6}$.
A chest radiograph showed marked cardiac $\frac{5}{3}$ enlargement. There was a pericardial effusion of 500 $\mathrm{ml}$ of straw-coloured fluid, and fibrocaseous material was also present in the epicardial sac looking almost purulent. Culture for tubercle bacilli was negative. Since then he has shown no signs of recurrence of his pericardial constriction, but his rheumatoid arthritis has remained active. He has been weaned off his steroid treatment and has taken penicillamine $500 \mathrm{mg}$ daily since 1979 . Latterly he has developed severe hand deformities with rupture of the extensor tendons of the left hand and has had to come to the Foot Clinic for severe foot problems. Renal function has been satisfactory, with a urea of $8.4 \mathrm{mmol} / \mathrm{l}$ and a creatinine clearance of $90 \mathrm{ml} / \mathrm{min}$, and this year his arthritis activity has at last of remitted.

\section{Histology (Dr B J Addis)}

The pericardium was grossly thickened, and pericar- dial sections showed an organising fibrinous exudate. T The granulations were infiltrated by lymphocytes and plasma cells. The pleura showed simple fibrous thickening. There was no evidence of tuberculosis.

TWO POSSIBLE FURTHER PATIENTS

The first was a white female aged 73 years witt rheumatoid arthritis since the age of 21 . She has been treated with steroids for over 20 years, and she had severe deformity of her hands and feet, with multiple erosions seen on hand and feet radiographs. She had typical elbow rheumatoid nodules. The plasma viscosity was $2.01 \mathrm{cP}$, the urea 8.1 $\mathrm{mmol} / \mathrm{l}$, and the serum Rose-Waaler titre was 1/2048. The antinuclear factor was positive without any DNA binding. Chest radiograph did not show any cardiac enlargement, but she had an enlarged liver and a loud pericardial friction rub. The ECG showed ST segment depression in leads I, II, AV $\mathrm{L}$, $\mathrm{V}_{5}$, and $\mathrm{V}_{6}$ with flattening of the $\mathrm{T}$ waves in the posterior leads. She refused any further investigation or treatment.

The second patient was a white male aged $69 \stackrel{\circ}{9}$ years with an 18 month history of rheumatoid $\frac{D}{0}$ arthritis. He was also known to have pneumoconiosis since his occupation as a quartz miller. He had $\stackrel{\sim}{\sigma}$ subcutaneous nodules at the elbows and moderate $N$ deformity of the hands. He had been treated at first with penicillamine and subsequently with predniso- $\omega$ lone $10 \mathrm{mg}$ daily, because his disease had not responded to the former. He had a persisting $\stackrel{O}{C}$ pericardial friction rub, a plasma viscosity of $2.63 \mathbb{\&}$ $\mathrm{cP}$, and a haemoglobin of $10.8 \mathrm{~g} / \mathrm{dl}(108 \mathrm{~g} / \mathrm{l})$. A chest radiograph showed a large heart, and he had ascites, hepatomegaly, and a raised jugular venous pressure. $\frac{\vec{D}}{\mathscr{D}}$ His ECG showed flat $\mathrm{T}$ waves in all leads. He then 
developed a widespread vasculitis and died suddenly before further investigation or treatment could be carried out. Permission for an autopsy was refused.

\section{Discussion}

It is interesting to note that in the survey of constrictive pericarditis reported by Sellors and his colleagues $^{10}$ rheumatoid arthritis was not even recognised as a cause, and the recent leader in the Lancet $^{7}$ made the same omission. In modern times the association of constrictive pericarditis with rheumatoid arthritis was probably not recognised until $1951,{ }^{11}$ and it still remains a rarity. As recently as 1975 only 46 patients with the association had been reported in the world literature. ${ }^{9}$ The constriction is thought to be a chronic, smouldering process that may persist for years, ${ }^{12}$ and the pericardial effusion and murmur may be recurrent and evanescent. This was shown by our patient No 2 , where the rub was heard only intermittently over a five year period, and in patient No 4 over a four year period. The condition has been reported in children, ${ }^{13}$ where it is particularly difficult to diagnose and may remain clinically 'silent', though, incidentally, Charcot recognised it in a child. ${ }^{2}$

The development of a pericardial rub (which may be difficult to hear) in a patient with rheumatoid arthritis who develops a persistent pleural effusion with hepatomegaly, elevation of the jugular venous pressure, and possibly ascites should certainly alert one to the diagnosis. However, the signs may mimic malignancy (patient 4) and even tuberculosis (patient 5), and this may confuse the investigator for a while. The duration of the rheumatoid disease before pericardial constriction becomes diagnosable has been reported as up to 20 years, with a mean of $12 \cdot 4$ years. ${ }^{5}$ In our series the longest duration was 12 years, with a mean of 9.4 years. This is in contrast with one study where it was thought not to occur in patients with arthritis of more than six years' duration. ${ }^{6}$ The physical signs of tamponade and constriction can be very confusing and the presence of a third heart sound is often difficult to ascertain with any certainty, and open to interpretation. However, a significant third heart sound is really the only difference in the physical signs between the two conditions and it may be difficult to hear. Paracentesis of the pericardium is a helpful way to confirm the presence of a pericardial effusion, though it is not always easy to do. The presence of fibrocaseous material in the pericardial sac as seen in patient 5 seems to be an intermediate stage between tamponade with its associated fluid, and frank constriction.

Echocardiography has been held to be the most useful investigation, ${ }^{5}$ though in two of the three patients reported here where it was done it was unhelpful. The ECG may be similarly of little help, as we found. Cardiac catheterisation appears to be the most accurate test. ${ }^{5}$ Left ventricular performance appears rarely to be depressed by constriction of the pericardium. ${ }^{14}$ However, constrictive pericarditis may be accompanied by healed arteritis, sclerosis, and granulomata in the aortic and mitral valve rings, and juxtaendocardial myocarditis. ${ }^{15}$ Coincidental coronary artery disease may be present, though it is rare for it to be complicated by heart block. ${ }^{16} \mathrm{~A}$ septic pericarditis complicating Felty's syndrome has been described, ${ }^{17}$ as has myocardial infarction caused by rheumatoid vasculitis in association with chronic pericarditis. ${ }^{18}$ Aortic incompetence may also be seen occurring with rheumatoid pericarditis. ${ }^{19}$

It is difficult to be certain how common pericarditis is in rheumatoid arthritis, let alone how often it progresses to constriction. The association of rheumatoid arthritis with constrictive pericarditis was thought to be present in four of 32 patients studied over 25 years in Dublin. ${ }^{20}$ Postmortem studies have shown pericarditis to be present in five of 25 patients in one study, though it has been reported as varying in prevalence from 11 to $50 \%{ }^{4}$ We found five definite and two possible examples of constrictive pericarditis in rheumatoid disease in life in a total of 2203 patients with rheumatoid arthritis referred to the department over the same period of time, of whom 1582 were female and 621 were male. Of our patients with a proved disease assocation, one was female and four were male. This gives a crude prevalence of $0.64 \%$ in males and $0.06 \%$ in females. Most studies have shown that constrictive pericarditis is commoner in males, ${ }^{58921-23}$ and they tend to have subcutaneous nodules, as we found. All were positive for rheumatoid factor, and three patients had a high Rose-Waaler titre, as has been observed before. ${ }^{6}$ The antinuclear factor was not a useful indicator, being positive in only two patients. The chest radiograph showed a considerably enlarged heart in four of the five, and renal function appeared to be impaired in four of the patients. The alkaline phosphatase was markedly raised in all five before surgery and reverted to normal after operation. Presumably this reflects preoperative cardiac embarrassment. The plasma viscosity indicated that the rheumatoid disease was very active in all of them. Follow up has ranged from nine months to 16 years (mean 5.75 years), and so far none of our patients have shown any signs of further pericardial constriction. All had erosions on hand and feet radiographs, and the mean age of pericardectomy was 52.4 years (38-63 years). Treatment with 
second-line therapy has not proved to be effective in preventing the development of pericarditis and subsequent constriction, as has been noted before, indeed medical treatment seems to be quite ineffective $^{5}$ and once the condition is diagnosed surgery is mandatory or the patient will die. Four of our five patients with proved disease association were treated with penicillamine in standard dosage, but although this proved effective in controlling their rheumatoid arthritis, it had no effect on the constrictive pericarditis. Steroid treatment has also been shown to be ineffective. ${ }^{15}$

We are grateful to both Mr S C Lennox and Mr M Paneth for allowing us to use the data from their operation reports, and to $\mathrm{Dr}$ B J Addis for permission to use the histological data. We remain very grateful to the Brompton Hospital for their great help in carrying out the surgical care of these patients.

\section{References}

1 Lower R. Tractatus de Corde. London, 1669.

2 Charcot J M. Clinical lectures on senile and chronic diseases. The New Sydenham Society 1881; 95: 172-5. (Translated by Tuke W S.)

3 Garrod A E. A treatise on rheumatism and rheumatoid arthritis. London: Charles Griffin, 1890.

4 Kennedy W P V. Partridge R E H, Matthews M B. Rheumatoid pericarditis with cardiac failure treated by pericardectomy. $\mathrm{Br}$ Heart J 1966; 28: 602-8.

5 Burney D P, Martin C E, Thomas C S. Fisher R D, Bender H W Jr. Rheumatoid pericarditis: clinical significance and operative management. J Thorac Cardiovasc Surg 1979; 77: 511-5.

6 Kirk J, Cosh J. The pericarditis of rhcumatoid arthritis. $Q J$ Med 1969; 38NS: 397-423.

7 Constrictive pericarditis. Lancet 1983; i: 1313-4.

8 John $\mathrm{J} \mathrm{T} \mathrm{Jr}$, Hough A. Sergent J S. Pericardial disease in rheumatoid arthritis. Am J Med 1979; 66: 385-90.

9 Thadani V. Iveson J M I. Wright V. Cardiac tamponade, constrictive pericarditis and pericardial resection in rheumatoid arthritis. Medicine (Baltimore) 1975; 54: 261-70.
10 Andrews G W S. Pickering G W, Sellors H T. The actiology oP constrictive pericarditis with special reference to tuberculou? pericarditis, together with a note on polyserositis. $Q J$ Med? 1948: 17: 291-321.

11 McMurray C. Cayer D. Cornatzer W E. Chronic adhesive pericarditis due to the rheumatic state. Gastroenterology 195 to 17: 294.

12 Nomeir A-M. Turner R A, Watts L E. Cardiac involvement ir rheumatoid arthritis: follow-up study. Arthritis Rheum 1979; 22= $561-4$.

13 Zadem Yousef D K. Fishman P A. The triad of pneumonitise pleuritis and pericarditis in juvenile rheumatoid arthritis Pediatr Radiol 1979; 8: 147-50.

14 MacDonald W J Jr, Crawford M H, Klippel J H, Zvaifler $\mathrm{N} \mathrm{J}$ O'Rourke R A. Echocardiographic assessment of cardiae structure and function in patients with rheumatoid arthritis. $A$ m J Med 1977: 63: 890-6.

15 Lebowitz W B. The heart in rheumatoid arthritis. A clinical an pathological study of sixty-two cases. Ann Intern Med 1963; 58 fै 102-23.

16 Gelson M A N, Sanderson J M, Carson P. Rheumatoid pericardial effusion with heart block treated by pericardectome and implantation of a permanent pacemaker. Br Heart J $1977 \mathrm{O}$ 39: $113-5$.

17 Shapiro L. Buckingham R B. Septic rheumatoid pericarditis complicating Felty's syndrome. Arthritis Rheum 1981; 24 1435-7.

18 Voyles W F, Searles R P. Bankhurst R D. Myocardiaf infarction caused by rheumatoid vasculitis. Arthritis Rheure 1980; 23: 860-3.

19 Iveson J M I, Thadami V, Ionescu M, Wright V. Aortic vadver incompetence and replacement in rheumatoid arthritis. Rheum Dis 1975; 34: 312-20.

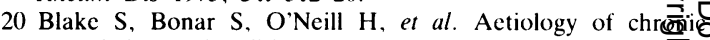
constrictive pericarditis. $\mathrm{Br}$ Heart $J$ 1983; 50: 273-6.

21 Baggenstoss A H, Rosenberg E F. Cardiac lesions associate with chronic infectious arthritis. Arch Intern Med 1941; 670 241-57.

22 Prakash R, Atassi A. Poske R. Rosen K M. Prevalence of pericardial effusion and mitral valve involvement in patient with rheumatoid arthritis without cardiac symptoms. $N$ Engl Med 1973; 289: 597-600.

23 Cosh J A, Iveson J M I. Constrictive pericarditis and rheuma toid arthritis. Ann Rheum Dis 1979: 38: 490-1. 